\title{
INVESTIGATION OF UNSTEADY FLOW IN AXIAL TURBINE STAGE
}

\author{
Tomáš JELÍNEK, Martin NĚMEC •
}

\begin{abstract}
The never ending process to increase the efficiency of turbine stages introduced an idea to create an axial turbine stage test rig as part of closed loop transonic wind tunnel at Vyzkumny a zkusebni letecky ustav (VZLU). Studying of unsteady flow field behaviours in turbine stages is nowadays essential in the development process. Therefore, the test rig was designed with focusing on possibility of detailed studying of unsteady flow fields in turbine stages.
\end{abstract}

New methodologies and new instrumentations were developed at VZLU and successfully integrated to gain valuable information from experiments with turbine stages. Two different turbine stages were tested during the facility introduction process. The measurement of these two models demonstrated how flexible the test rig is. One of them was an enlarged model of small gas turbine stage. The other was scaled-down model of stage of intermediate-pressure steam turbine. The external characteristics of both models were acquired during experiments as well as the detailed unsteady flow field measurement. Turbine stages were tested in various regimes in order to check the capabilities of the facility, methodology and instrumentation together.

The paper presents results of unsteady flow field investigation in the enlarged turbine stage with unshrouded rotor. The interaction of structures developed in a stator with the rotor flow field is depicted and the influence of turbine load on evolution of secondary flows in rotor is analysed.

\section{INTRODUCTION}

Turbomachinery is a traditional field of research at VZLU. It began with experimental research of flow fields in linear cascades, what is basic task in the turbomachinery. This case is relatively easy to arrange, therefore results can be very interesting, namely for the development of procedures of numerical simulations and studying of physical processes in blade cascades (for example [1, 2]). Further step in the research was done by arranging experiments in annular cascades [3]. Very interesting experiences with recording of three-dimensional structures in turbine stator were obtained. Original methodology [4] was arranged for these experiments. It is applicable especially for measurement of complicated periodical structures in small channels of turbines. This is extremely interesting for the following work focused on the research of unsteady flow fields in turbine stages.

\footnotetext{
- Tomáš Jelínek, Výzkumný a zkušební letecký ústav, Beranových 130, Praha 9, jelinek@vzlu.cz Martin Němec, výzkumný a zkušební letecký ústav, Beranových 130, Praha 9, nemec@vzlu.cz
}

This is an Open Access article distributed under the terms of the Creative Commons Attribution License 2.0, which permits unrestricted use, distribution, and reproduction in any medium, provided the original work is properly cited. 


\section{TEST FACILITY, INSTRUMENTATION AND MODEL DESCRIPTION}

The test rig is part of the closed loop wind tunnel powered by $1.3 \mathrm{MW}$ electro-engine. Parameters of the test rig are shown in Table 1. Tested turbine is loaded by Froude Hofmann F249-Race GT dynamometer and the test rig is equipped with HBM T10FS torque meter fixed on turbine's shaft to ensure more accurate torque measurement.

Concept of the rotatable stator of measured stage was used in consequence of linear probe manipulators. This idea was motivated by several reasons which make the measurement and follow-up data analyses more convenient $[5,6]$.

\begin{tabular}{|l|l|}
\hline Maximum rotational speed & $15000 \mathrm{rpm}$ \\
\hline Mass flow rate & $6 \mathrm{~kg} \cdot \mathrm{s}^{-1}$ \\
\hline Maximum brake power & $700 \mathrm{~kW}$ \\
\hline Maximum expansion ratio & 8 \\
\hline Accuracy of torque measurement & better then $\pm 0.5 \mathrm{Nm}$ \\
\hline
\end{tabular}

Table 1: Parameters of test rig

\begin{tabular}{|l|l|}
\hline Nominal rotational speed & $13700 \mathrm{rpm}$ \\
\hline Tip diameter stator / rotor & $0.318 / 0.321 \mathrm{~m}$ \\
\hline Number of blades stator / rotor & $26 / 41$ \\
\hline Rotor tip clearance & $1 \mathrm{~mm}$ \\
\hline
\end{tabular}

Table 2: Parameters of the turbine stage

To be able to study the unsteady measurement it is necessary to place the pressure transducer as near the investigation point in flow field as possible. For this reason the probes equipped with pressure transducers mounted in their tips were developed [7].

Data in flow field were acquired in the plane at the outlet of the rotor $15 \mathrm{~mm}$ behind the plane of rotor blades trailing edges (see Figure 1). Two wakes of stator were traversed through during experiments.

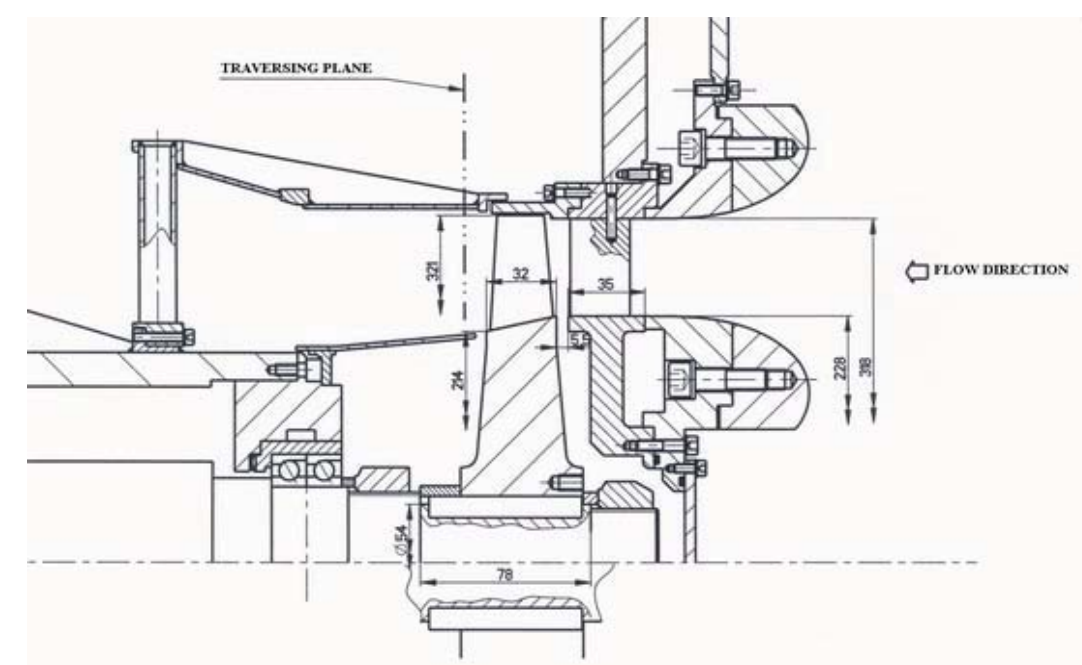

Figure 1: Cross-section of investigated turbine stage TJ100

Note, that the traverse plane is quite far from the rotor trailing edges, therefore the structures could be partially mixed. 


\section{Methodologies}

The methodology is based on the one used for stator flow field investigation [4]. There are three probes mounted with angular distance $60^{\circ}$. These probes together give complete information about flow parameters in each measured point. Data from all probes are acquired simultaneously and numerically synchronized with reference mark on the shaft. The methodology is roughly described in [5], detailed description is written in [8].

The experimental setup was the same for both studied regimes. Data from all probes were acquired with sampling frequency $410 \mathrm{kHz}$. This corresponds to approximately 50 points per the rotor blade channel, 60 rotor revolutions were recorded in each point. Then average rotor revolution is computed from the time record and finally flow field parameters are evaluated. This is done at each captured point.

Local efficiency coefficient and energy coefficient are presented in this paper as a support of analysis. The local efficiency coefficient is defined as a ratio of local efficiency and integral efficiency. The energy coefficient is defined by following expression and basically it has a sense of the kinetic energy weighted by the flow density in axial direction.

$$
c_{E}=q_{a} \cdot\left(\frac{v}{a_{r e f}}\right)^{2}
$$

where $q_{a}$ is normalised flow density in axial direction

$$
q_{a}=\frac{(\rho \cdot v)_{a}}{(\rho \cdot a)_{r e f}}
$$

The combination of these parameters was chosen for the capability of flow structures identification.

\section{FLOW FIELD STRUCTURES IN A STAGE OF AXIAL TURBINE}

The flow structures in a turbine cascade are briefly shown here. Typical models of loss mechanisms in annular cascades are depicted in Figure 2. Flow structures in an annular cascade consist of a core flow (CF), where the lowest losses are presented. This part of the flow field is surrounded by the loss structures. Boundary layers developed on the blade surfaces create a wake behind the trailing edge (W) and there are also boundary layers on the casing walls. More complicated structures are caused by secondary flows in the channel. The main structure is a passage vortex (PV), what is a result of a pressure gradient across the channel. This gradient causes an end wall cross flow and finally the passage vortex as a result of an interaction of the cross flow with the core flow. This vortex is surrounded by next vortices. A horseshoe vortex is formatted on the leading edge. This vortex is shifted by the passage vortex in midspan direction. Under the passage vortex, a corner vortex (CV) is generated. Interactions in the region of these vortices lead to strong deformation of the blade wake.

Moreover, strong vortex is created by the flow that goes over the tip of the blade in the case of the unshrouded rotor blade. It is called the tip leakage vortex (TLV) and it strongly affects other structures. It shifts other structures more to the center of the blade height and interacts with them. 
At the end - it is necessary to keep in mind, that the stage is composited of the stator and the rotor. The stator loss structures are choped by the rotor blades, where similar structures are developed. During their interaction, the stator structures are transported in various ways. Simple blade-vortex transport model is drawn in Figure 2d.

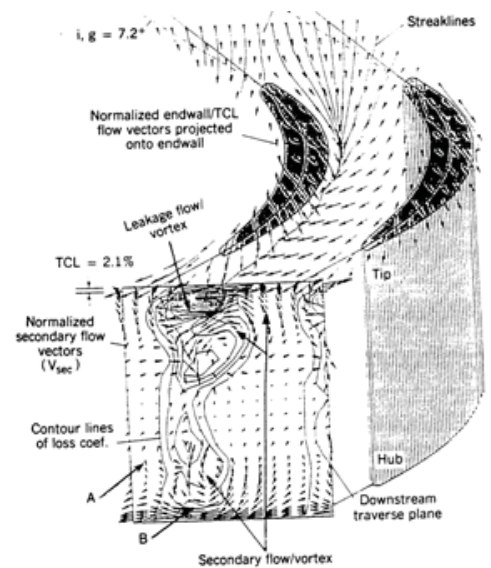

a) Yamamoto [9]

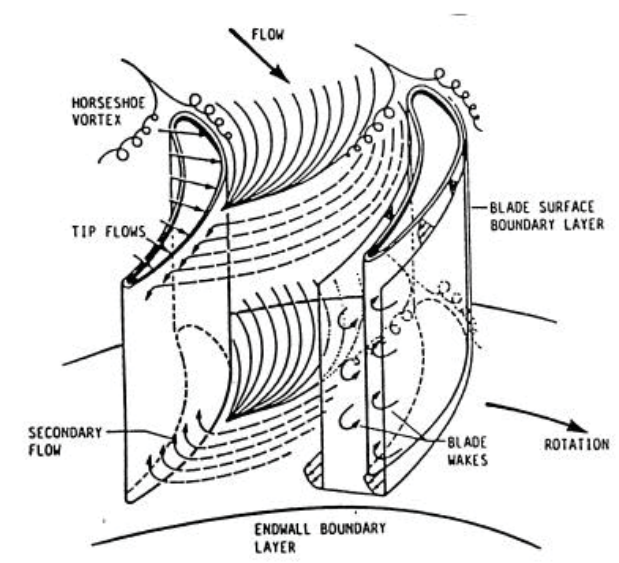

c) Denton [11]

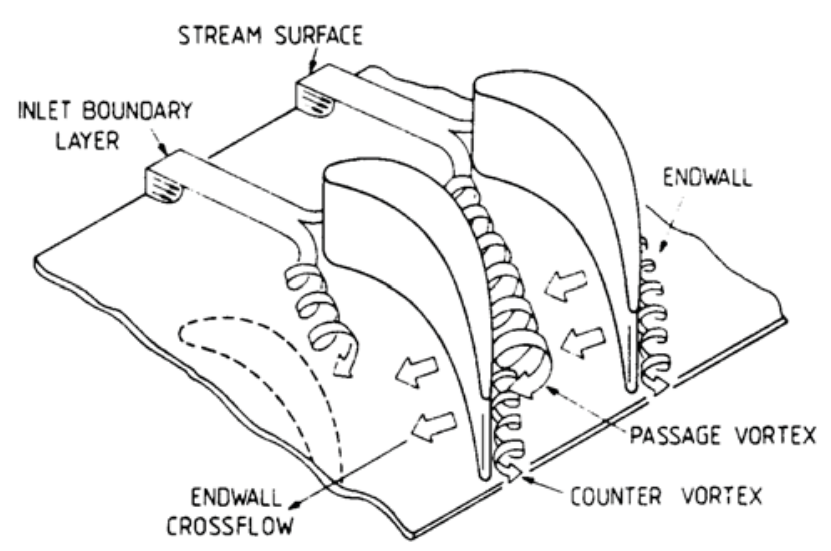

b) Sieverding [10]

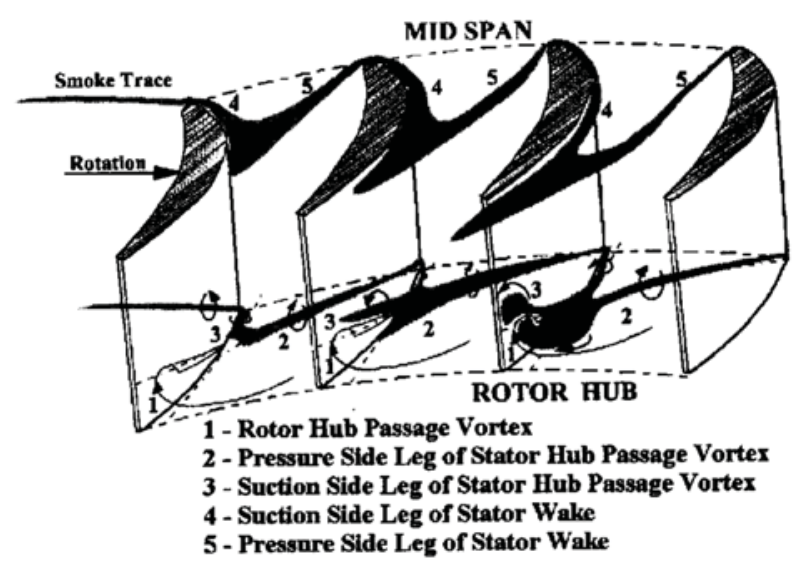

d) Chaluvadi [12]

Figure 2: Loss structures in an axial turbine stage

\section{THE INFULENCE OF STAGE LOAD ON THE FLOW FIELD IN UNSHROUDED TURBINE STAGE}

The influence of the load of the stage was studied on TJ100 turbine stage. Two regimes are analysed here - the first one is the turbine in near to a nominal conditions and the second one is an overloaded turbine in regime with slightly lower expansion ratio in comparison with the nominal one. Interestingly the integral efficiency of the stage is well comparable in both cases. Both studied regimes are described using basic parameters in the following Table 3. Parameters written in this table are given here in order to support the results of the analysis.

\section{Integral stage parameters}

The integral parameters we will discuss firstly. We are comparing two regimes with comparable efficiencies, but most of the parameters of the stage are completely different. The only thing that is the same in both cases is the regime of the stator. There 
is almost the same outlet Mach number and outlet angle. As a consequence, energy losses will also be the same in both regimes (supported by background not presented here). It therefore means that changes are mainly caused by the development of the flow field in the rotor.

\begin{tabular}{|c|c|c|c|}
\hline Parameter & & Nominal regime & $\begin{array}{l}\text { Off-design } \\
\text { regime }\end{array}$ \\
\hline Expansion ratio & [1] & 2.85 & 2.2 \\
\hline Velocity ratio $\mathrm{u} / \mathrm{c}$ & [1] & 0.48 & 0.4 \\
\hline Efficiency & [1] & $1 \cdot \eta$ & $0.99 \cdot \eta$ \\
\hline Stage reaction & [1] & 0.43 & 0.26 \\
\hline Rotor inlet relative angle & {$\left[{ }^{\circ}\right]$} & 25 & 40 \\
\hline Rotor outlet absolute angle & {$\left[{ }^{\circ}\right]$} & 10 & 3 \\
\hline Stator outlet Mach number & [1] & 0.86 & 0.85 \\
\hline Rotor inlet relative Mach number & {$[1]$} & 0.48 & 0.52 \\
\hline Rotor outlet relative Mach number & [1] & 0.84 & 0.65 \\
\hline Rotor outlet absolute Mach number & [1] & 0.43 & 0.39 \\
\hline
\end{tabular}

Table 3: Integral parameters - comparison of studied regimes

The combination of changed expansion ratio with the same stator regime leads to the necessity of the stage reaction adaptation. The turbine with lower expansion ratio works with lower reaction, thereby the expansion in rotor is weaker and finally we can expect that the cascade in such a regime will not be able to sufficiently suppress the development of loss structures. Moreover, the turbine with lower expansion ratio is overloaded and thus the rotor relative inlet angle increases. It is higher by $15^{\circ}$ in comparison with the nominal regime. Therefore we can expect lot of non-uniformities in the flow field in studied off-design regime.

When the expansion ratio is increased, the reaction also has to increase. Now, the rotor works with more intensive expansion and it is able to greatly suppress development of loss structures. On the other hand, increased expansion ratio increases relative outlet velocity. In the nominal regime, a transonic region on the blade suction side is developed, which causes an increase of the energy losses in the flow field. It is the most probable reason for comparable efficiency of studied regimes.

\section{Time averaged flow field}

Figure 3 shows time averaged distributions of local efficiency and energy coefficients. The nominal regime is on the left-hand side, figures on the right-hand side show the regime that represents the overloaded turbine. The regions with low energy are highlighted by contours in all graphs. These regions correspond to the strongest interactions of the stator secondary flow with the rotor flow structures. The geometrical shape of the stator trailing edge (STE) is also drawn in these pictures (solid line) together with the approximate shape of the stator wake (SW - dashed line).

The strongest structures we can observe are the regions of the stator passage vortices the hub passage vortex (SHPV) and the tip passage vortex (STPV). Near the casing there is a casing vortex and in the centre of the channel the core-flow (CF) with the highest energy and local efficiency. 
Comparison of these two regimes clearly shows the influences of the stage load on the flow field. These results are in accordance with the analysis made with support of the integral parameters. It was said before, that both regimes have a comparable integral efficiency. The main difference consists of the flow parameters distribution. In general, the nominal regime has a more uniform flow field in comparison with the overloaded one. On the other hand, deformation of the stator wake is in the case of the nominal regime stronger. It is in accordance with the distribution of the Mach number, flow angle and efficiency combined. At the same time it is necessary to highlight, that the wake in the case of the nominal regime is highly suppressed and its effect is very weak.

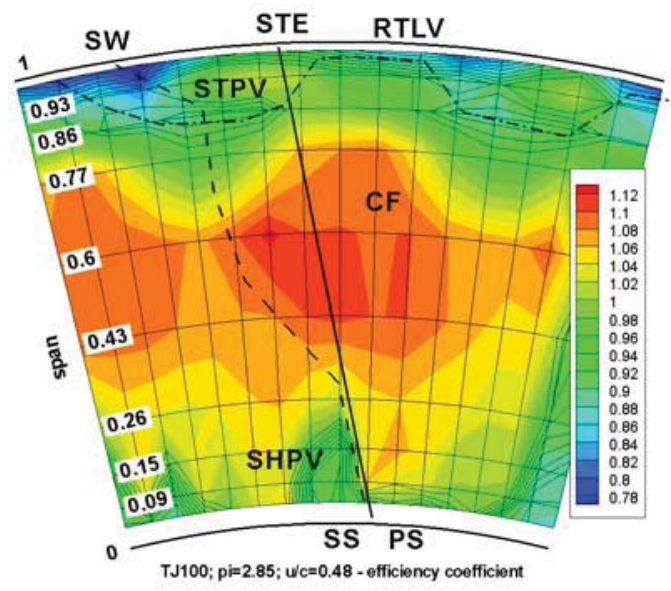

a) efficiency coefficient - nominal

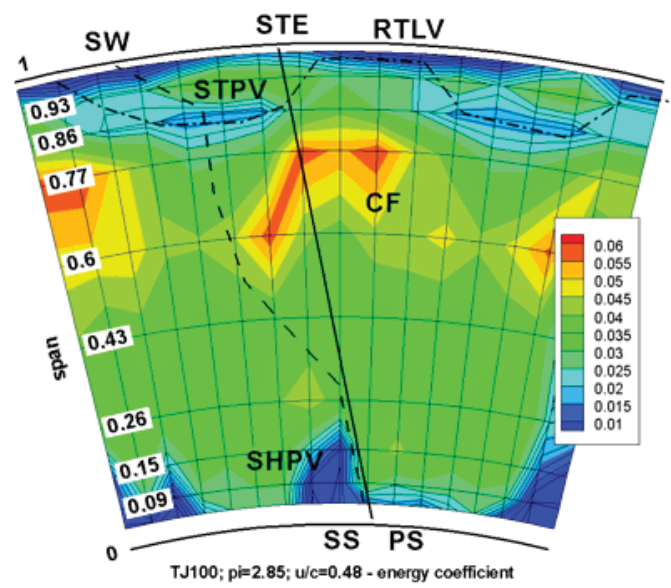

c) energy coefficient - nominal

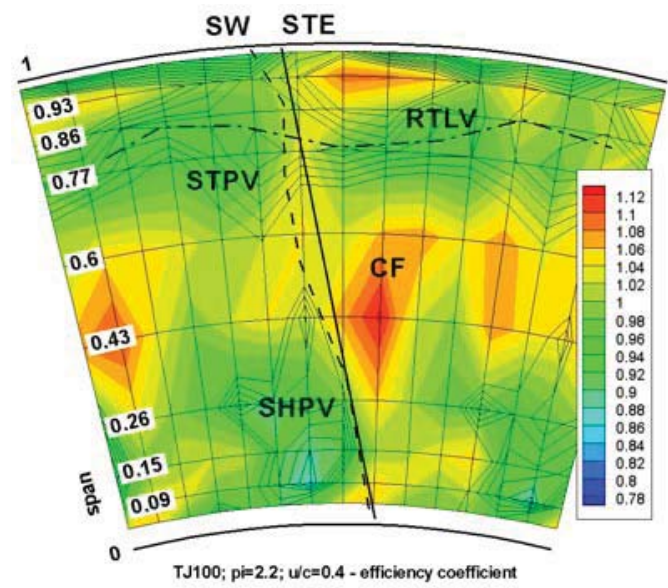

b) efficiency coefficient - off-design

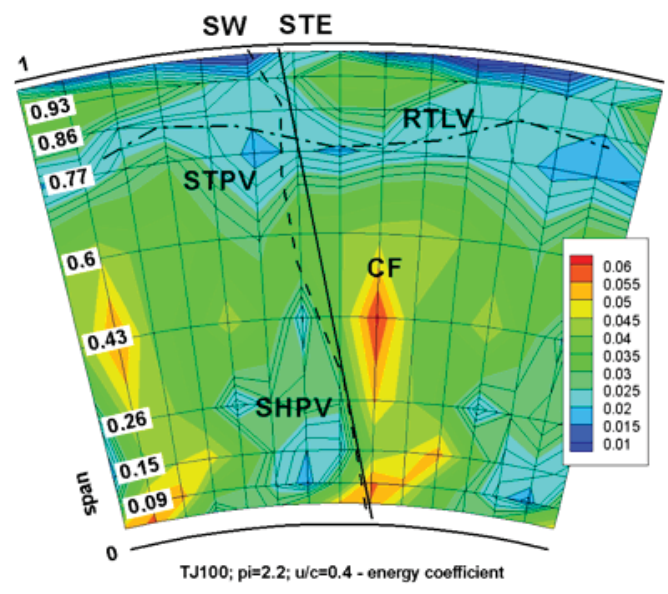

d) energy coefficient - off-design

Figure 3: Time averaged flow field parameters distributions

The core flow occupies more than $40 \%$ of the outlet area in the case of the nominal regime. It is in contrast with the overloaded stage, where there is just a small area with the core flow. Together with a comparable integral efficiency it supports the conclusion, that the absolute value of the efficiency in the core flow is lower in the case of the nominal regime.

Mentioned small area of the core flow in the case of the overloaded turbine is caused by strong interactions of the stator and the rotor secondary flows. This interaction is boosted 
by the rotor inlet conditions and generally by the rotor regime as discussed previously. The flow in the rotor is destabilized by the high inlet angle and as a result supports strong development of secondary structures which are finally shifted in the midspan direction. These structures are well suppressed by the expansion in the rotor row in the nominal regime and the core flow drives them out of the centre. It is also described in the following text, where details of the flow field structures are briefly discussed.

In the case of the nominal regime, the loss structures are concentrated in the relatively small regions. The stator hub passage vortex is centred at $10 \%$ of the span and the tip passage vortex at $86 \%$ of the span. The hub passage vortex seems to be stronger than the tip one. On the other hand the tip passage vortex occupies a bigger area in the circumferential direction which is caused by the interaction between the stator passage vortex and the rotor tip leakage vortices.

In the case of the overloaded stage, the loss structures are situated more to the centre of the span. The most intensive region of the hub passage vortex is situated at $10 \%$ (similarly to the case of the nominal regime). It is weaker in comparison to the nominal regime, but occupies wider area (encroaches even to $43 \%$ of the span). The centre of the tip passage vortex is shifted to the position $77 \%$ of the span and again occupies a wider area around the centre. Moreover the path of the rotor tip leakage vortices (RTLV) is clearly visible across whole periphery (dash-dotted line). The rotor tip leakage vortex oscillates between values of $77 \%$ and $86 \%$ of the span. It is possible to obtain an estimation of the tip leakage vortices strength from the fact that a part of the core flow is separated by the vortices and is kept near to the casing (see the region of high efficiency close to the tip passage vortex in fig. $3 b$ ).

\section{Unsteady flow field}

Time averaged distributions showed locations of the most intensive interaction regions. In this part, we will compare unsteady behaviours of the flow fields. As a support for the analysis, instantaneous distributions of the energy coefficient are drawn in following figures. In these figures, the interaction regions found in the time averaged distributions are again highlighted. Displayed time sequences catch the passing of one rotor blade period. In the case of the nominal regime it corresponds to time $0.1 \mathrm{~ms}$, the time period of the overloaded regime corresponds to $0.15 \mathrm{~ms}$.

Firstly, we will analyze the off-design regime.

The most intensive structure in the flow field is the low-energy region near the blade tip. With respect the plane of observation, the tip leakage region is formatted by the interaction of the tip leakage vortex and the rotor tip passage vortex - tip leakage vortex label is further used for this region.

We will observe the development of the flow field in relation to rotor blade number 3 .

At time $t / T=0$ blade 3 just left the region of the strongest stator-rotor interaction. The shape of loss structures is similar to those behind the blade 2 at time $t / T=0.6$. The interaction of the rotor wake with the stator structures is partially fading in the bottom part of the span.

Typical distribution behind the rotor blade we can see at time $t / T=0.2$ - there is the rotor wake with the hub passage vortex (RHPV) and the tip leakage vortex (TLV). At this time, the stator secondary flow is not present in the blade channel 2-3 (channel between the blades 2 and 3), therefore the core-flow is moving towards the casing to the region, where we have seen part of the core-flow closed by the loss structures. 

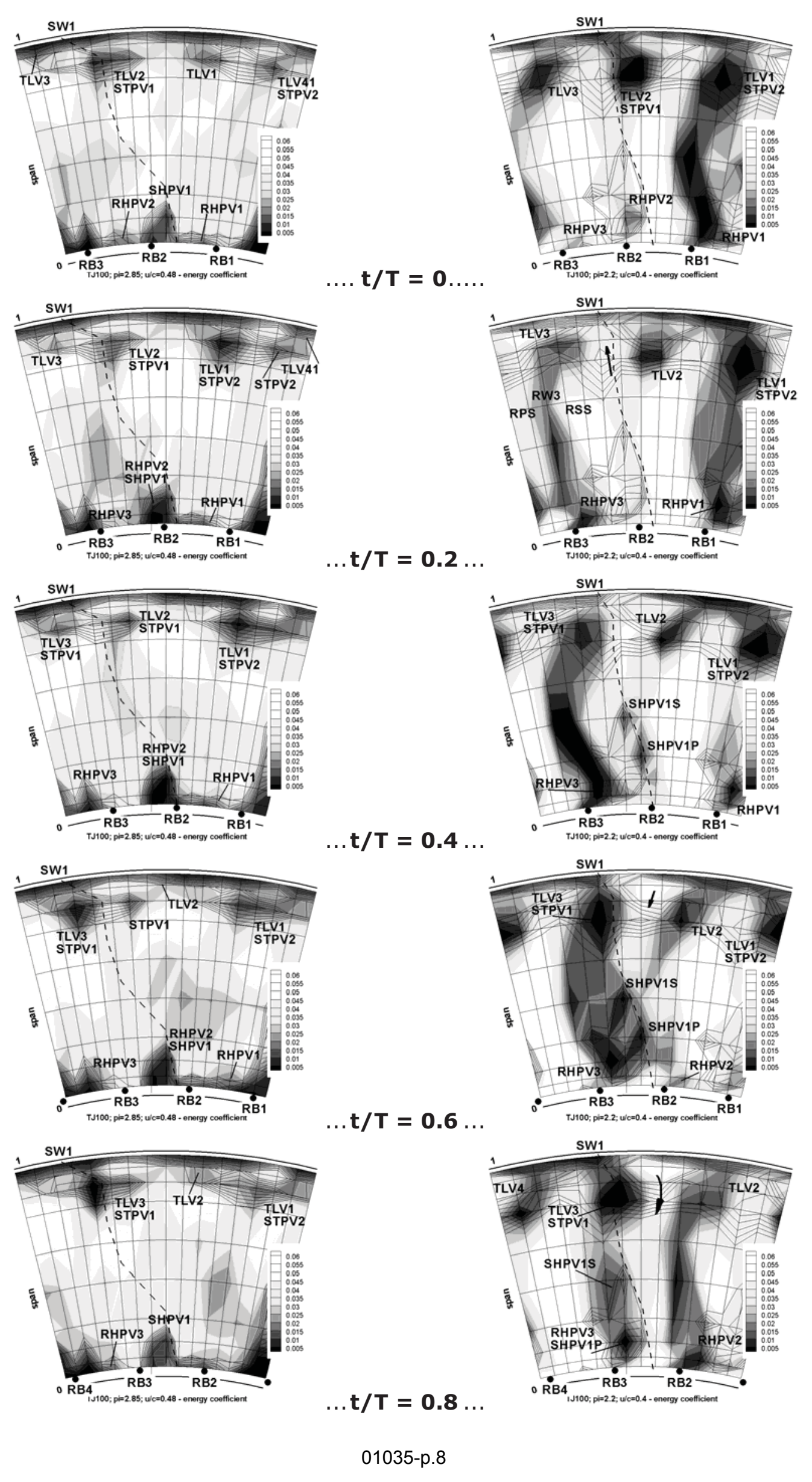
Time $t / T=0.4$ corresponds to a beginning of the main stator-rotor interaction. The tip leakage vortex is powered by the stator tip passage vortex (both are clockwise-rotating) and it starts to grow. The rotor wake and the hub passage vortex are also stronger. The stator hub passage vortex (SHPV) probably appears in two parts. The first one is in the position $43 \%$ of the span, the second in the position $26 \%$ of the span. This is caused by the vortex transportation in the rotor. Stator passage vortex has two counter-rotating legs - rotor suction side and rotor pressure side (according to [12]) - because the vortex is chopped by rotor blade and distributed to both suction and pressure sides of the blade. On the blade suction side, the stator passage vortex (counterclockwise) interacts with the horseshoe vortex (counterclockwise) and is shifted towards the mid-span by the rotor passage vortex (clockwise). The pressure side leg (SHPV1P - clockwise) is moved by the crossflow in the blade channel under the suction side leg (SHPV1S). It is also shifted upwards and finally interacts with the rotor hub passage vortex.

The interaction is fully developed at time $t / T=0.6$. The tip leakage vortex together with the stator tip passage vortex is beginning to empty the tip part of the core-flow, the interaction of the rotor blade boundary layer with the stator wake and other loss structures leads to a separation on the rotor suction side and finally to huge widening of the rotor wake. The stator influence is at this time so strong, that affects the distribution in whole channel 2-3, it also means structures behind the adjacent blade number 2 .

The interaction in the tip region is still very strong and discharging of the tip core-flow region is the most intensive at time $t / T=0.8$. In the hub region, the rotor hub passage vortex engulfs the pressure side leg of the stator hub passage vortex. The suction side leg is weakening and is positioned right under $43 \%$ of the span.

The expansion in the rotor blade row causes distinct suppression of unsteady structures in the case of the nominal regime.

Let's summarize the action in the hub region. The stator hub passage vortex is well stabilized and just small variation of the energy coefficient is possible to see. These fluctuations are caused by the interaction of the rotor and stator hub passage vortexes. The transportation of the stator structures in the rotor seems distinctly simpler in comparison with the off-design regime. It is caused by the suppression of the loss structures in the rotor row. The expansion in the rotor blade row presses all structures down to the hub casing and therefore we can see them only partially.

In the tip region, the flow field is more active. The tip leakage vortex is kept by the expansion near to the casing - similar situation with the rotor hub passage vortex. It appears only in the regions where the interaction with the stator tip passage vortex occurs. At time $t / T=0$ we can see the tip leakage vortex just before the interaction (we are again traveling with the blade number 3 ). At the same time, the interaction of the tip leakage vortex of the blade 2 with the stator tip passage vortex is the most intensive.

Time $t / T=0.2$. The tip leakage vortex number 3 is pulled by the stator tip passage vortex down to the position $86 \%$ of the span and the interaction is in the beginning. The interaction of the blade 2 with the stator tip passage vortex still survives.

At time $t / T=0.4$, the interaction of the tip leakage vortex 3 with the stator tip passage vortex is well developed and becomes stronger. Simultaneously, the interaction of the tip leakage vortex 2 keeps its position and begins fading.

At the next time step $t / T=0.6$, the interaction of the tip leakage vortex 3 with the stator passage vortex is fully developed and it's moving towards the region, where the second part of the tip passage vortex is. This part of the vortex is a rest of the interaction with 
the adjacent blade 2 . The tip passage vortex 2 wriggled out of the interaction and leaped back to the casing.

Two parts of the stator tip passage vortex are joined together at time $t / T=0.8$.

Except of the analysed details of the flow fields we can do general comparison of time sequences. Similarly to the deformation of stator wake found in the time averaged distributions, the unsteady structures are shifted by the same way. It is possible to see on different relative positions of the blade marks and rotor structures. These marks have the same positions in both cases thanks to the synchronization with the shaft reference mark. The rotor structures are shifted in left-hand direction in the case of the nominal regime in comparison with the off-design regime. It is caused mainly by different time averaged outlet angle.

\section{Conclusion}

The investigation of unsteady flow field in the unshrouded turbine stage demonstrated how complicated in this case the flow field is. Basically these first experiments were focused on the verification of the facility and methodologies arrangement. With the help of the analysis results it was proved, that both - the facility and methodologies - are well suitable for the investigation of unsteady flow fields in turbine stages. It was possible to detect typical structures of the unsteady flow field behind the rotor of unshrouded turbine. These results are excellent for following process of the development focused on improving of methodologies used in these experiments.

The comparison of flow fields in presented regimes showed, that evolution of the flow in the rotor row is essential for the stage behaviours. These results again show, that reasonable expansion in turbine blade row is capable to diminish a lot of loss structures which are present at the inlet and which are self-developed. Lower expansion boosts the development of loss structures, what we have seen in the case of the overloaded turbine. Strengthening of the loss structures extends area occupied by low-energy regions and consequently may cause higher losses in following parts of the machine (difuser; nozzle; next stages in multi-stage turbine etc.).

Distributions captured in these experiments show, that only detail measurement of the flow field parameters is able to provide sufficiently reliable data for the analysis of turbine stage behaviours.

\section{ACKNOWLEDGMENTS}

The support of this project from the Ministry of Industry and Trade under the grant No FT-TA5/067 is gratefully acknowledged. 


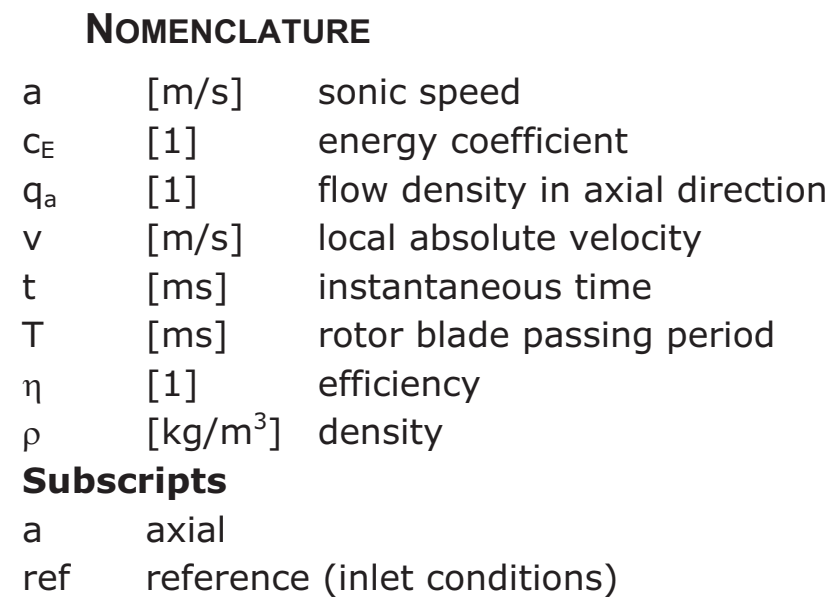

\section{REFERENCES}

[1] Ulrych J., Jelinek T., Benetka J., Valenta R., Tajc L.: Experimental Research of Surface Roughness Impact on Transonic Flow in Blade Cascades, Thessaloniki, The XVIII Symposium on Measuring Techniques in Turbomachinery, 2006

[2] Nemec M., Jelinek T., Benetka J.: The influence of Air Humidity in High-speed Aerodynamics in Turbomachinery Applications, Praha, Czech Aerospace Proceedings 4/2010, 2010

[3] Nemec M., Straka P., Jelinek T., Babak M.: On the Developement of Short Axial Lenght Turbine Stator with Outlet Mach Number 2, Glasgow, ASME Turbo Expo 2010, GT2010-22490, 2010

[4] Nemec M., Michalek J., Strach V.: Method of average flow parameters evaluation, Thessaloniki, The XVIII Symposium on Measuring Techniques in Turbomachinery, 2006

[5] Jelinek T., Nemec M.: The axial turbine stage test rig, Plzen, Turbomachinery 2010, 2010 (Czech language)

[6] Nemec M., Jelinek T., Benetka J.: Test turbine VZLU - integral characteristics measurement, Praha, report VZLU R-4939, 2010 (Czech language)

[7] Nemec M.; Development of pressure probes for unsteady measurement in turbomachinery, Plzen, Power System Engineering, Thermodynamics \& Fluid Flow - ES 2009, 2009 (Czech language)

[8] Nemec M., Jelinek T., Benetka J.: Test turbine VZLU - detailed flow field measurement, Praha, report VZLU R-4940, 2010 (Czech language)

[9] Yamamoto A.: Endwall Flow/Loss Mechanisms in a Linear Turbine Cascade, Jnl. of Turbomachinery, Volume 111, Issue 3, July 1989, p. 264-276

[10] Sieverding, C. H.: Recent Progress in the Understanding of basic Aspects of Secondary Flow in Turbine Blade Passages, Jnl. of Engineering for Gas Turbines and Power, Volume 107, Issue 2, April 1985, p. 248-258

[11] Denton J. D.: Axial turbine aerodynamic design, Lecture note for an advanced course on Turbomachinery Aerodynamic, University of Cambridge, 1994

[12] Chaluvadi V. S. P., Kalfas A. I., Banieghbal M. R., Hodson H. P., Denton J. D.: Blade-Row Interaction in a High-Pressure Turbine, AIAA Jnl. of propulsion and power, Volume 17, No. 4, July-August 2001, p. 892-901 